\author{
Military Technical College \\ Kobry El-Kobbah, \\ Cairo, Egypt.
}

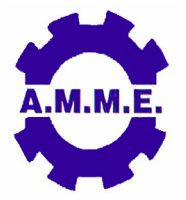

\title{
TORSIONAL ACTUATION OF ORTHOTROPIC BEAM USING INCLINED PIEZOELECTRIC PATCHES
}

\author{
M. A. Elshafei ${ }^{\star}$ A. A. Omer ${ }^{\star}$ and A. M. Farid*
}

\begin{abstract}
The objective of this research is to develop a finite element model for the analysis of the static response of a composite compressor blade subjected to extension, transverse, and torsion loads in addition to the torsion actuation due to the piezoelectric patches. The equation of motion is derived based on classical beam theory with warping effect is taken into consideration, using the principle of the virtual displacement of the structure system. A one dimensional linear isoperimetric element with Lagrange and hermit cubic shape functions is used to model the axial and transverse deformation. A two end nodes and an intermediate one as well are implemented for modeling the torsion deformation. The bending, torsion and axial coupling are introduced in the stiffness and mass matrices. The electric potential is treated as a generalized electric coordinates like the generalized displacement coordinates. A MATLAB interactive code is developed to solve a blade with mechanical and electrical loads. The obtained results are found reasonable.
\end{abstract}

\section{KEY WORDS}

Finite element method, compressor blade design, composite materials mechanics, warping, structural analysis.

\footnotetext{
* Egyptian Armed Forces.
} 


\section{NOMENCLATURE}

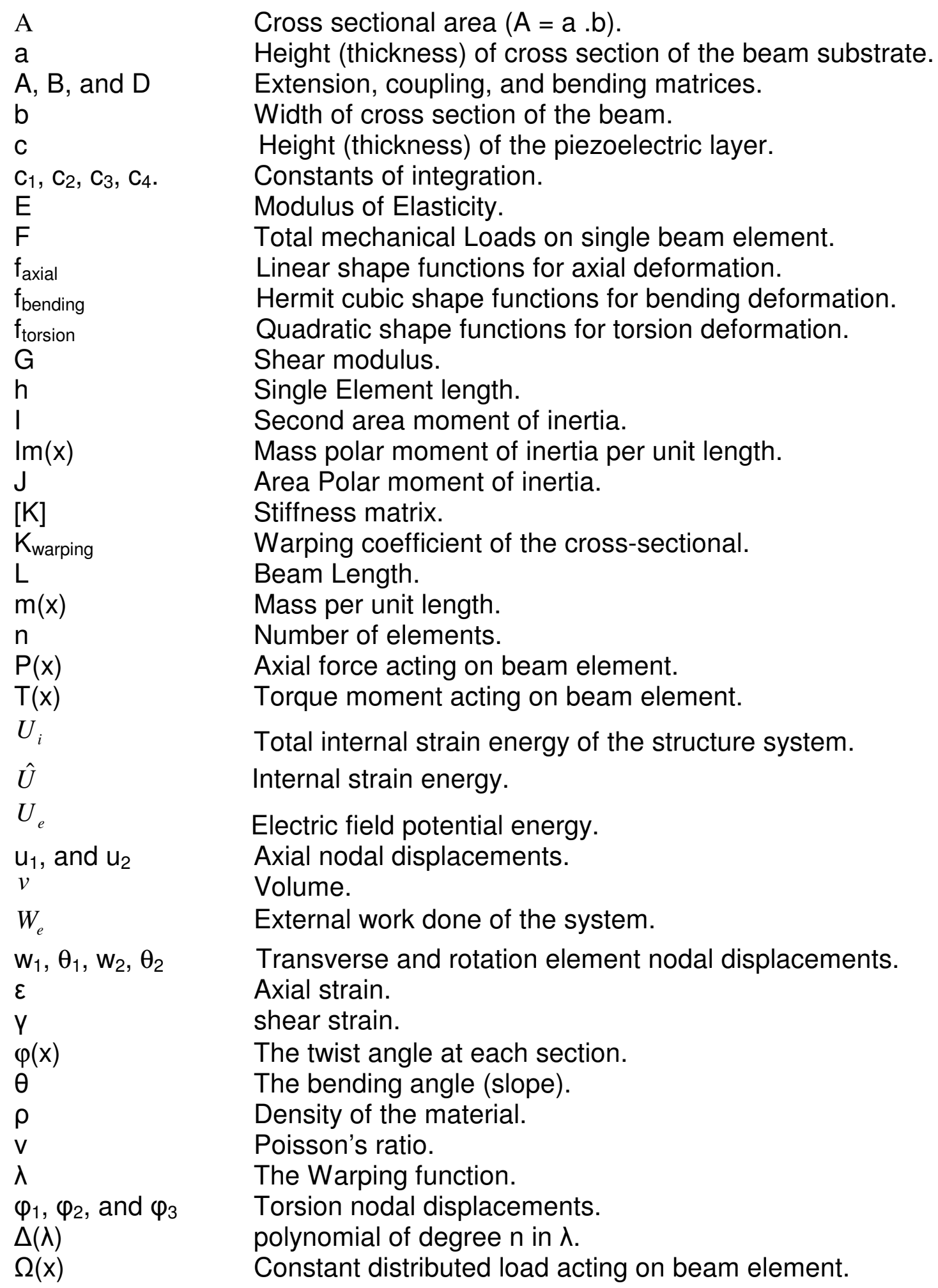




\section{INTRODUCTION}

The critical structural elements of a typical gas turbine engine are the compressor or turbine disk carrying several blades around its circumference. These units operate in severe environments characterized by high speeds of rotation and cycle temperatures. Most of the failures reported have been due to vibration-induced fatigue of blade. The objective is to improve the dynamic performance of the engine blade and reduce vibration to an acceptable level and reduce stresses. It is shown that incorporating smart structure technology in engine blades can give desirable shape control characteristics to improve the blade at all of these areas at a reasonable weight.

Modeling of beam structures with coupled behavior (torsion-bending) has been investigated by few authors. Sakawa and Luo [1], used a shear-deformable theory to model a mass coupled beam, the internal beam damping was included in the model and the actuation torque was applied to the shaft by a motor. Banks and Smith [2], studied a coupling problem where the warping effects and the internal shear damping were considered in their model. Banerjee and Williams [3], studied the vibration of a beam with geometrical coupling by a Timoshenko beam theory, they ignored the warping effect. Suresh et al [4] showed that warping effects can significantly influence the natural frequencies of a composite beam. The inclusion of the transverse shear deformation becomes necessary in beams with a small width to thickness ratio for isotropic beams [5]. The warping effects caused by St. Venant and warping torsion were explicitly included in the Sankar's model [6]. Elshafei et al. [7-8], developed finite element model to get static and dynamic response of compressor blades subjected to multi mechanical loads they took the warping effect into consideration. Their models were for isotropic and anisotropic structures. The obtained results were found reasonable.

The behavior of smart structures has received considerable attention in the literature. Crawley and de Luis [9] presented an analytical uniform strain model of a beam with strain induced actuation by use of surface bonded piezoceramic for beam extension, bending included the shear lag effects of the adhesive substrate layer. Bailey and Hubbard [10] and Fanson and Chen [11], Sunar and Rao [12], and Benjeddou [13] demonstrated the possibility of using piezoelectric materials for beam vibration control. Allik and Hughes [14] presented a tetrahedral finite element for 3-D electro-elasticity. Based on this model Tzou [15] proposed a method for isotropic plate analysis using isoperimetric hexahedron solid elements. Chandrashekhara et. al. [16] developed a model based on the first order shear deformation theory which needs a shear correction coefficient. Based on a simple higher order shear deformation theory (by Reedy), Elshafei et. al. [17] developed a finite element model for isotropic and orthotropic smart beams using Bernoulli-Euler theory. All of these models assume that the actuators are aligned with and symmetrically located with respect to the beam axis and most of them assumed a constant variation of the electric field through thickness the piezoelectric layers.

Few papers have developed the analysis of intelligent structures with coupled behavior (torsion-bending). Park and Chopra [18], proposed a model to predict the coupled extension, bending and torsion responses of a beam subjected to piezoelectric strain actuation. Their experimental test results show that the models 
are accurate up to 45 degree actuators orientation with respect to the beam axis. A shear lag is introduced to attenuate bending, extension and torsion responses. Park et al. [19], formulate two additional shear lag models one of them permitted an arbitrary orientation of the piezoelecrtric patches with respect to the beam axis to predict coupled extension, bending, and torsion. The model utilized a Newtonian shear lag formulation in which the strain was assumed to be constant through the thickness of the actuator and linear through the beam. Takawa et al [20], proposed an experiment of the piezoelectric actuators attached perpendicular to the principle axis of elasticity of the beam for controlling the torsional vibration mode of the beam. They obtained the natural frequencies of flexural and torsion vibration. Chen and Chopra [21], developed a fraud scale helicopter rotor blade with piezoelectric elements placed at positive and negative forty five degree angle with respect to the beam axis, they predict the static bending and torsion response of the structure. Although the magnitudes of blade twist attained in this experiment were small, it is expected that future models can built with improved performance. Elshafei et al. [22], proposed a model for the analysis of compressor blade subjected to mechanical and electrical load using inclined piezoelectric actuators. The torsion response is obtained and compared with available analytical results and found reasonable.

In the present studies modeling intelligent structures subjected to combined extension, bending, and torsional loads in addition to induced strain actuation developed by forty five degree actuators orientation with respect to the beam axis. A Matlab code is prepared to obtain the static response of the proposed structure system.

\section{THEORITICAL FORMULATION}

The compressor blade is modeled as an advanced beam under the assumptions of Euler-Bernoulli theory of beam. The structure is subjected to axial, transverse, and torsion loads. The bending and torsional deformations are shown in Figures 1 and 2.

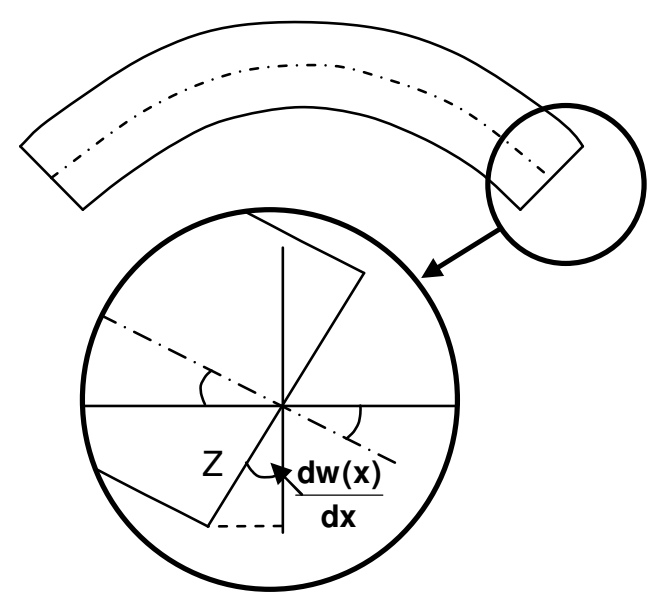

Figure 1: Bending displacement.

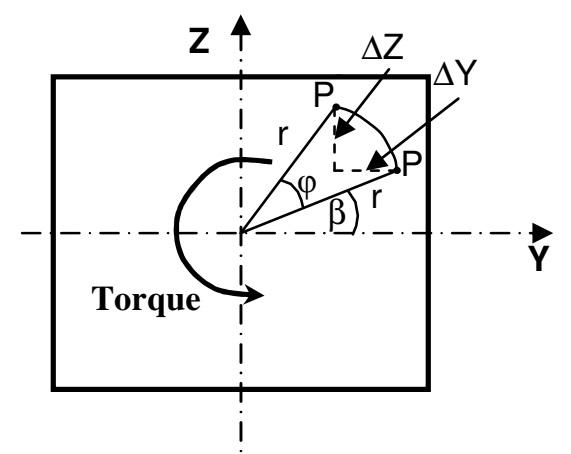

Figure 2: Torsion displacement. 
The following formulations are obtained [23]:

$$
\Delta Y=r \cdot \cos (\beta+\varphi)-r \cdot \cos (\beta)
$$

where $\varphi$ is the twist angle for each section " $\mathrm{x}$ ". For small angle $\varphi, \cos (\varphi) \cong 1$, $\sin (\varphi) \cong \varphi$, therefore,

$$
\Delta Y=-\varphi \cdot r \cdot \sin (\beta)
$$

Since, $\quad \Delta Y=-Z \cdot \varphi=-Z \cdot X \cdot \theta$

$$
Z=r \cdot \sin (\beta)
$$

where, $\theta$ twist is the twist angle per unit length. Similarly,

$$
\begin{aligned}
& \Delta Z=r \cdot \sin (\beta+\varphi)-r \cdot \sin (\beta) \\
& \Delta Z=\varphi \cdot r \cdot \cos (\beta) \\
& \Delta Z=Y \cdot \varphi=Y \cdot X \cdot \theta
\end{aligned}
$$

Thus the assumed displacements field equations based on the classical beam theory at any point in the $\mathrm{x}, \mathrm{y}$, and $\mathrm{z}$ directions are:

$$
\begin{aligned}
& U(x)=u_{S}(x)-z \cdot \frac{\partial w(x)}{\partial x}-z \cdot y \cdot \frac{\partial \phi(x)}{\partial x} \\
& V(x)=-z \cdot \phi(x) \\
& W(x)=w(x)+y \cdot \phi(x)
\end{aligned}
$$

where $u_{s}(x), w(x)$, and $\phi(x)$ are the axial displacement, the bending displacement, and the torsion twist angle, respectively. The warping function of a bar with non circular cross section must satisfy following two conditions:

$$
\begin{gathered}
\nabla^{2} \lambda=\frac{\partial^{2} \lambda}{\partial y^{2}}+\frac{\partial^{2} \lambda}{\partial z^{2}}=0 \\
\left(\frac{\partial \lambda}{\partial y}-z\right) \cdot \frac{d z}{d s}-\left(\frac{\partial \lambda}{\partial z}-y\right) \cdot \frac{d y}{d s}=0
\end{gathered}
$$

From these conditions, the warping function can be written as:

$$
\lambda=K_{\text {warping }} \cdot y \cdot z
$$

where $K_{\text {warping }}$ is the warping coefficient of the cross section area. For beam with rectangular cross section area $K_{\text {warping }}=1$. 


\section{Strain-Displacement Relations}

The strain displacement relations can be given as:

$$
\begin{aligned}
& \varepsilon_{x x}=\frac{\partial U_{s}(x)}{\partial x}-z \cdot \frac{\partial^{2} w(x)}{\partial x^{2}}-z \cdot y \cdot \frac{\partial^{2} \phi(x)}{\partial x^{2}} \quad \gamma_{x y}=-2 z \cdot \frac{\partial \phi(x)}{\partial x} \\
& \varepsilon_{y y}=0 \quad \varepsilon_{z z}=0 \quad \gamma_{z x}=0 \quad \gamma_{z y}=0
\end{aligned}
$$

\section{The Piezoelectric Relationships}

The piezoelectric constitutive relations

The linear piezoelectric constitutive equations can be expressed as [24-25]:

$$
\left[\begin{array}{l}
\sigma_{x x} \\
\sigma_{x y} \\
D_{z}
\end{array}\right]=\left[\begin{array}{ccc}
\bar{Q}_{11} & \bar{Q}_{16} & 0 \\
\bar{Q}_{16} & \bar{Q}_{66} & 0 \\
e_{31} & 0 & 0
\end{array}\right]\left[\begin{array}{c}
\varepsilon_{x x} \\
\gamma_{x y} \\
0
\end{array}\right]-\left[\begin{array}{c}
e_{31} \\
0 \\
-\varepsilon_{z z}^{s}
\end{array}\right] E_{z}
$$

(The transformation reduced stiffness coefficients $\bar{Q}_{i j} \quad$ [N/m2], are given in the Appendix).

where $[D]$ is the electric displacement $[\mathrm{C} / \mathrm{m} 2],[e]$ is the electric permittivity matrix $\left[\mathrm{C} / \mathrm{m}^{2}\right],[\varepsilon]$ is the strain vector, $\left[\mathcal{\varepsilon}^{s}\right]$ is the dielectric matrix at constant strain $[\mathrm{F} / \mathrm{m}]$, $[E]$ is the electric field $[\mathrm{V} / \mathrm{m}]$, and $[\sigma]$ is the stress vector $\left[\mathrm{N} / \mathrm{m}^{2}\right]$.

\section{Induced strain and electrical forces}

Assuming that the actuators have high aspect ratio, the piezoelectric patch is approximated as only inducing a strain along its longitudinal axis. The induced strain is thereby transformed to beam axes as shown in Figure 3 [26]:

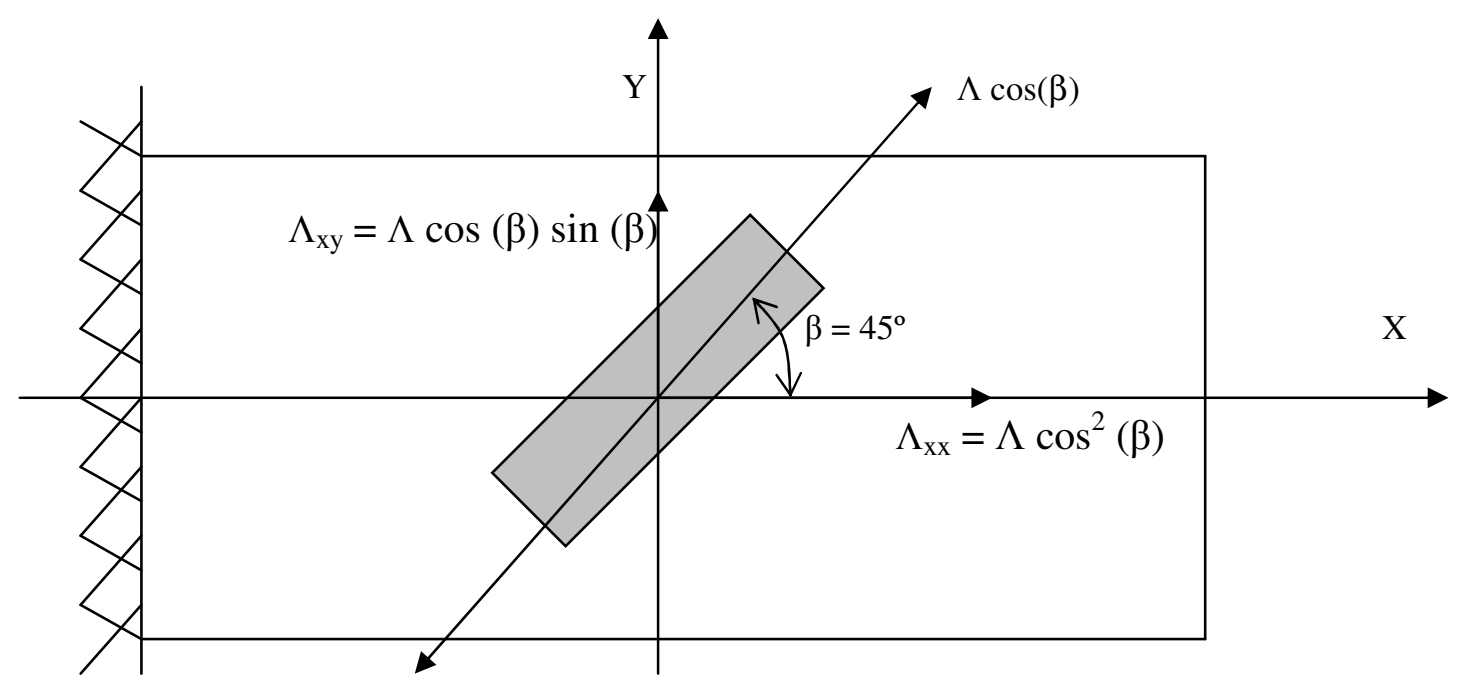

Figure 3: Piezoelectric strain when the patch is inclined to the beam axis. 


$$
\Lambda_{x x}=\Lambda \cos ^{2}(\beta) \quad \Lambda_{x y}=\Lambda \cos (\beta) \sin (\beta)
$$

Where; $\wedge$ is the electrical strain of piezoelectric patch $\left(\wedge=\frac{\text { Applied.voltage }}{\text { thickness }} . d_{31}\right)$, and $\beta$ is the inclination angle of the piezoelectric patch with the beam axis. The electrical piezoelectric forces due to induced strain are expressed as follows:

Axial induced electrical forces:

$$
F_{\text {axial }}=\int_{A} \bar{Q}_{11} \cdot \Lambda_{x x} \cdot d A
$$

Bending induced electrical moments are

$$
F_{\text {bending }}=\int_{A} \bar{Q}_{11} \Lambda_{x x} \cdot z \cdot d A
$$

Torsion induced electrical moments are

$$
F_{\text {torsion }}=\int_{A} \bar{Q}_{66} \cdot \Lambda_{x y} \cdot z \cdot d A
$$

\section{Variational Formulation}

The equations of motion can be obtained using the variation approach by equating the internal strain energy and the virtual work expressions such as [17]:

$$
\delta U_{i}=\delta W_{e}
$$

Thus the internal strain energy for the structure system $U_{i}$ is the sum of internal strain energy $\hat{U}$, and the electric field potential energy $U_{e}$, such as [13-27-28-29]:

$$
U_{i}=\frac{1}{2} \int_{v}\left(\hat{U}+U_{e}\right) d v
$$

Where the internal strain energy $\hat{U}$ is represented by:

$$
\hat{U}=\frac{1}{2} \int_{v} \varepsilon_{k l} \sigma_{i j} d v
$$

And the electric energy $U_{e}$ is expressed by:

$$
U_{e}=\frac{1}{2} \int_{v} E_{k} D_{i} d v
$$

Thus; $\quad U_{i}=\frac{1}{2} \int_{v}\left[\left(\sigma_{x x} \varepsilon_{x x}+\sigma_{x y} \gamma_{x y}\right)-\left(D_{z} E_{z}\right)\right] d v$

$$
U_{i}=\frac{1}{2} \int_{v}\left[\left(\bar{Q}_{11} \varepsilon_{x x}+\bar{Q}_{16} \gamma_{x y}-e_{31} E_{z}\right) \varepsilon_{x x}+\left(\bar{Q}_{16} \varepsilon_{x x}+\bar{Q}_{66} \gamma_{x z}\right) \gamma_{x z}-\left(e_{31} \varepsilon_{x x}+\varepsilon_{z z}^{s} E_{z}\right) E_{z}\right] d v
$$




$$
\begin{aligned}
& U_{i}=\frac{1}{2} \int_{v}\left[\left(\bar{Q}_{11} \varepsilon_{x x}^{2}+\bar{Q}_{16} \gamma_{x y} \varepsilon_{x x}+\bar{Q}_{16} \varepsilon_{x x} \gamma_{x y}+\bar{Q}_{66} \gamma_{x y}^{2}-e_{31} E_{z} \varepsilon_{x x}-e_{31} \varepsilon_{x x} E_{z}-\varepsilon_{z z}^{s} E_{z}^{2}\right)\right] d v \\
& \delta U_{i}=\int_{v}\left[\delta \varepsilon_{x x}^{T} \bar{Q}_{11} \varepsilon_{x x}+\delta \varepsilon_{x x}^{T} \bar{Q}_{16} \gamma_{x y}+\delta \gamma_{x y}^{T} \bar{Q}_{16} \varepsilon_{x x}+\delta \gamma_{x y}^{T} \bar{Q}_{66} \gamma_{x y}-\delta E_{z}^{T} e_{31} \varepsilon_{x x}-\delta \varepsilon_{x x}^{T} e_{31} E_{z}-\delta E_{z}^{T} \varepsilon_{z z}^{s} E_{z}\right] d v
\end{aligned}
$$

By inserting Eqn. (7) for the induced strain into Eqn. (15), one can obtain:

$$
\delta U_{i}=\int_{v}\left[\begin{array}{l}
\delta\left(\varepsilon_{x x}-\Lambda_{x x}\right)^{T} \bar{Q}_{11}\left(\varepsilon_{x x}-\Lambda_{x x}\right)+\delta\left(\varepsilon_{x x}-\Lambda_{x x}\right)^{T} \bar{Q}_{16}\left(\gamma_{x y}-\Lambda_{x y}\right)+\delta\left(\gamma_{x y}-\Lambda_{x y}\right)^{T} \bar{Q}_{16}\left(\varepsilon_{x x}-\Lambda_{x x}\right) \\
+\delta\left(\gamma_{x y}-\Lambda_{x y}\right)^{T} \bar{Q}_{66}\left(\gamma_{x y}-\Lambda_{x y}\right)-\delta E_{z}^{T} e_{31}\left(\varepsilon_{x x}-\Lambda_{x x}\right)-\delta\left(\varepsilon_{x x}-\Lambda_{x x}\right)^{T} e_{31} E_{z}-\delta E_{z}^{T} \varepsilon_{z z}^{s} E_{z}
\end{array}\right] d v
$$

Thus; the elements of the stiffness matrix

$$
k_{u u}=\int_{v}\left[\begin{array}{l}
\delta\left(\varepsilon_{x x}-\Lambda_{x x}\right)^{T} \bar{Q}_{11}\left(\varepsilon_{x x}-\Lambda_{x x}\right)+\delta\left(\gamma_{x y}-\Lambda_{x y}\right)^{T} \bar{Q}_{66}\left(\gamma_{x y}-\Lambda_{x y}\right) \\
+\delta\left(\varepsilon_{x x}-\Lambda_{x x}\right)^{T} \bar{Q}_{16}\left(\gamma_{x y}-\Lambda_{x y}\right)+\delta\left(\gamma_{x y}-\Lambda_{x y}\right)^{T} \bar{Q}_{16}\left(\varepsilon_{x x}-\Lambda_{x x}\right)
\end{array}\right] d v
$$

\section{Elastic matrix}

$$
\begin{array}{ll}
k_{u \varphi}=\int_{v}\left[\delta\left(\varepsilon_{x x}-\Lambda_{x x}\right)^{T} e_{31} E_{z}\right\rfloor d v & \text { Mechanical electric coupling matrix } \\
k_{\varphi u}=\int_{v}\left[\delta E_{z}^{T} e_{31}\left(\varepsilon_{x x}-\Lambda_{x x}\right)\right] d v & \text { Electric mechanical coupling matrix } \\
k_{\varphi \varphi}=\int_{v}\left[\delta E_{z}^{T} \varepsilon_{z z}^{s} E_{z}\right] d v & \text { Electric matrix }
\end{array}
$$

The virtual work expressions can be represented as:

$$
\delta W_{e}=\delta W_{M e c h}+\delta W_{E l e c}
$$

Where, $\delta W_{\text {Mech }}$ and $\delta W_{\text {Elec }}$ are the two components of the virtual work due to a mechanical and the electrical loads; respectively.

$$
\begin{gathered}
\delta W_{\text {Mech }}=\int_{0}^{h} P(x) \cdot d x . \delta u_{S}(x)+\int_{0}^{h} \Omega(x) \cdot d x . \delta w(x)+\int_{0}^{h} T(x) \cdot d x . \delta \varphi(x) \\
\delta W_{\text {Elec }}=\delta W_{\text {axial }}+\delta W_{\text {bending }}+\delta W_{\text {torsion }} \\
\delta W_{\text {axial }}=E_{\text {piezo }} \int_{A} \Lambda_{x x} d A \delta u
\end{gathered}
$$




$$
\begin{aligned}
\delta W_{\text {bending }} & =E_{\text {piezo }} \int_{A} \Lambda_{x x} z d A \delta w \\
\delta W_{\text {torsion }} & =G_{\text {piezo }} \int_{A} \Lambda_{x y}\left[\left(y-\frac{\partial \lambda}{\partial z}\right)-\left(z+\frac{\partial \lambda}{\partial y}\right)\right] d A \delta \varphi
\end{aligned}
$$

$$
\text { Since } \lambda=y z
$$

Thus;

$$
\delta W_{\text {torsion }}=-2 G_{\text {piezo }} \int_{A} \Lambda_{x y} z d A \delta \varphi
$$

The element mass matrix is obtained using the kinetic energy term as follows:

$$
\begin{aligned}
& T(t)=\frac{1}{2} \int_{0}^{L} m(x) V^{2} d x \\
& =\frac{1}{2} \int_{0}^{L}\left(m(x) \dot{\bullet}^{2}+m(x) \dot{\bullet}^{2}+\rho \cdot I_{x}(x) \dot{\varphi}^{2}\right) \cdot d x
\end{aligned}
$$

Where $\rho$ is the density of the material, $V$ is the velocity (displacement differentiation), and $m(x)$ is the mass per unit length of the beam.

\section{Finite Element Formulation}

The Nodal displacements for axial, bending and torsion displacements are termed as; " $u_{1}, u_{3}$ ", " $w_{1}, \theta_{1}, w_{3}, \theta_{3}$ " and " $\varphi_{1}, \varphi_{2}, \varphi_{3}$ " respectively, in addition to two degrees of freedom of electric potential $\Phi_{1}$ and $\Phi_{2}$ which are illustrated in the Figure 4.

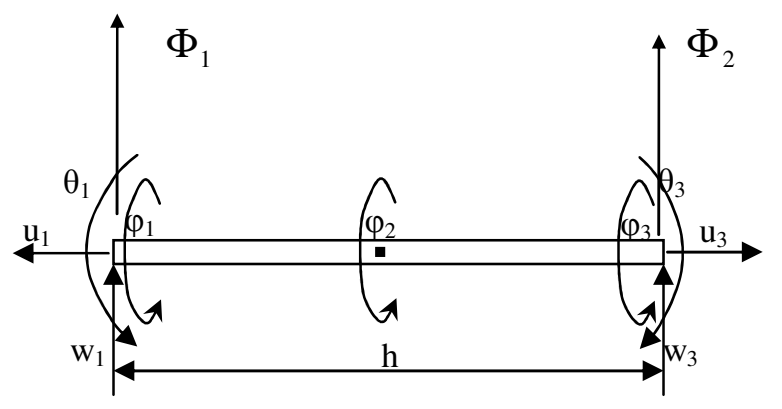

Figure 4: Nodal Displacements of axial-bending-torsion Element and electric potential.

Linear shape function is used for the axial deformation $u_{s}(x)$ [7-30]:

$$
f_{\text {axial }}=\left[\left(1-\frac{x}{h}\right) \frac{x}{h}\right]
$$

The transverse deformation $w(x)$ is expressed in terms of a hermit cubic shape function [7]: 


$$
f_{\text {bending }}=\left[\left[1-3\left(\frac{x}{h}\right)^{2}+2\left(\frac{x}{h}\right)^{3}\right]\left[\frac{x}{h}-2\left(\frac{x}{h}\right)^{2}+\left(\frac{x}{h}\right)^{3}\right]\left[3\left(\frac{x}{h}\right)^{2}-2\left(\frac{x}{h}\right)^{3}\right]\left[-\left(\frac{x}{h}\right)^{2}+\left(\frac{x}{h}\right)^{3}\right]\right]
$$

For the three nodal displacements on beam element as shown in Figure 4 the shape function of the torsion displacements $\varphi(x)$ can be expressed in terms of quadratic interpolation function as follows [7]:

$$
f_{\text {torsion }}=\left[\left[2\left(\frac{x}{h}\right)^{2}-3\left(\frac{x}{h}\right)+1\right]\left[-4\left(\frac{x}{h}\right)^{2}+4\left(\frac{x}{h}\right)\right]\left[2\left(\frac{x}{h}\right)^{2}-\left(\frac{x}{h}\right)\right]\right]
$$

For the piezoelectric element, the electric field is treated as the electric degrees of freedom like a generalized displacement degrees of freedom [17]. The governing equation for the electric potential is given by:

$$
-\nabla^{2} \varphi=0
$$

By solving Eqn. (39) and applying the boundary condition, the electric potential takes the form in axial direction such as:

$$
\Phi(x)=\left[\begin{array}{ll}
(1-x / h) & (x / h)
\end{array}\right] \cdot\left[\begin{array}{l}
\Phi_{1} \\
\Phi_{2}
\end{array}\right]
$$

And in the transverse direction through the thickness of the piezoelectric layer can be written as:

$$
\Phi(z)=\left[\left(\frac{1}{2}+\frac{z}{a}\right)\left(\frac{1}{2}-\frac{z}{a}\right)\right] \cdot\left[\begin{array}{l}
\Phi_{1} \\
\Phi_{2}
\end{array}\right]
$$

In the present work, the electric potential is considered to be a function of the thickness and the length of the beam. Therefore, the electric shape function at the nodal element, represented by multiplying the shape function Eq. (27) by the first term of shape function Eq. (28). Homogenous boundary conditions for the electric potentials will be imposed on the bottom surface to eliminate rigid body modes. Thus the shape functions finally take the form [17]:

$$
\Phi(x, z)=\left[\left(\frac{1}{2}+\frac{z}{a}\right)\left(1-\frac{x}{L}\right)\left(\frac{1}{2}+\frac{z}{a}\right)\left(\frac{x}{L}\right)\right] \cdot\left[\begin{array}{c}
\Phi_{1} \\
\Phi_{2}
\end{array}\right]
$$

The electric field vector $E_{z}$ can be expressed as:

$$
E_{Z}=-\nabla \cdot \Phi(x, z)=\frac{-\partial \Phi}{\partial Z}=\left[-\frac{1}{a} \cdot\left(1-\frac{x}{L}\right)-\frac{1}{a} \cdot\left(\frac{x}{L}\right)\right] \cdot\left[\begin{array}{c}
\Phi_{1} \\
\Phi_{2}
\end{array}\right]
$$




\section{Equation of Motion}

By substituting the shape functions Equations (24), (25), (26), and (31), into Equations (18), (20), (21), and (23), the structure element stiffness matrix, both the electrical and the mechanical force vectors, and the element mass matrix are obtained. The equation of motion of the whole structure system is represented by:

$$
\left[\begin{array}{cc}
M_{\text {ии }} & 0 \\
0 & 0
\end{array}\right]\left\{\left\{\begin{array}{l}
\ddot{U}\} \\
\{\ddot{\varphi}\}
\end{array}\right\}+\left[\begin{array}{ll}
{\left[K_{\text {uu }}\right]} & \left\lfloor K_{u \varphi}\right] \\
{\left[K_{\varphi q u}\right]} & {\left[K_{\varphi \varphi}\right.}
\end{array}\right]\left\{\left\{\begin{array}{l}
U U\} \\
\{\varphi\}
\end{array}\right\}=\left\{\begin{array}{l}
\{F\} \\
\{Q\}
\end{array}\right\},\right.\right.
$$

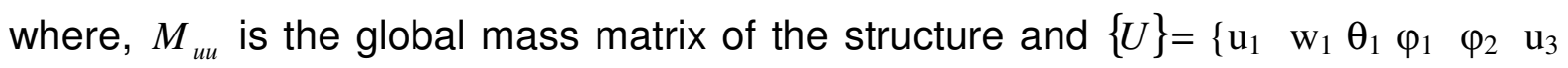
$\left.w_{3}, \theta_{3} \varphi_{3}\right\}$ is the global nodal generalized displacement coordinates, $\{\varphi\}$ is the global nodal generalized electric coordinates vector describing the applied voltage at the actuators [16], $\{F\}$ is the applied mechanical load vector, and $\{Q\}$ is the electric excitation vector.

The total response of the beam under the action of piezoelectric actuator patch in the static analysis can be obtained as:

Where;

$$
\left\{q_{\text {total }}\right\}=\left[K_{\text {total }}\right]^{-1} \cdot\left[F_{\text {total }}\right]
$$

$$
K_{\text {total }}=\left[K_{q q}\right]+\left[K_{q \Phi}\right] \cdot\left[K_{\Phi \Phi}\right]^{-1} \cdot\left[K_{\Phi q}\right]
$$

and;

$$
\left[F_{\text {total }}\right]=[F]+\left[K_{q \Phi}\right] \cdot\left[K_{\Phi \Phi}\right]^{-1} \cdot[Q]
$$

\section{VALIDATION EXAMPLES}

A MATLAB code is developed to check the validity of the present model. The code is able to analyze smart beam structures subjected to different mechanical and electrical loads with inclined piezoelectric patches. The input data are the geometric and materials properties, applied loads, and the boundary condition as shown in Figure 5.

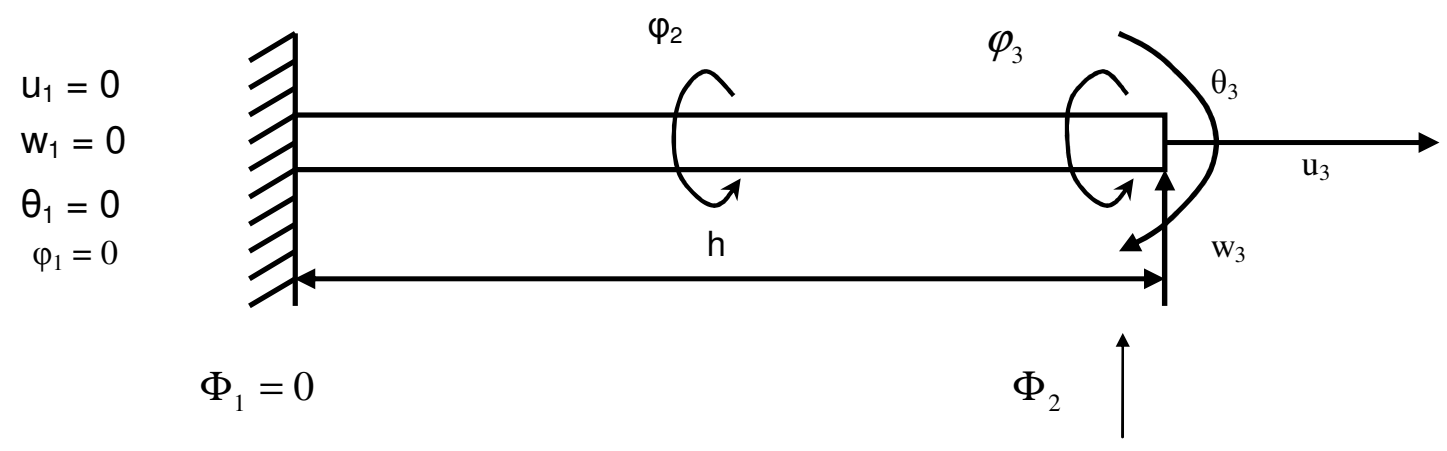

Figure 5: Degrees of freedom for Fixed-Free beam element. 
The model results are checked first by solving the structure substrate as isotropic material and the obtained results compared to the prediction shown in Ref. [22-26]. Second by comparing the obtained results to the predictions presented given by Ref. [27-28], as shown in example (1).

\section{Example (1)}

In this section, the accuracy and verification of the model is illustrated by comparing the obtained results with the generalized model of Robbins and Reddy [27], and the model of Sarvanos and Heyliger [28]. Three layers $\left[0^{\circ} / 90^{\circ} / 0^{\circ}\right]$ of $(\mathrm{T} 300 / 934)$ Graphite/Epoxy composite beam with piezoelectric material (PZT-4) completely covered the surface without inclination angle is used. In such case the electric force is expressed as:

$$
\{Q\}=\int_{S_{1}} \delta \Phi \cdot \mu \cdot d S_{1}
$$

where, $\mu$ is the surface charge density $(\mathrm{C} / \mathrm{m} 2)$ applied to the piezoelectric surface area $S_{1}$, and $\Phi$ is the electric potential (volt). The obtained results given in Table (1) are found in good shape in comparison with the Refs. [27-28].

The properties of the composite beam substrate and the piezoelectric layer are as follows:

Composite beam dimensions (T300/934 Graphite/Epoxy):

$$
\begin{array}{lll}
L_{\text {comp }} & =0.1524 & \text { meter } \\
\mathrm{a} & =0.01524 & \text { meter }
\end{array}
$$

Piezoelectric dimensions (PZT-4):

\begin{tabular}{|c|c|c|c|}
\hline $\mathrm{E}_{1}$ & $=126.174$ & $\mathrm{GPa}$ & Modulus of elasticity in longitudinal direction. \\
\hline $\mathrm{E}_{2}$ & $=7.86$ & $\mathrm{GPa}$ & Modulus of elasticity in transverse direction. \\
\hline $\mathrm{G}_{12}$ & 3.447 & GPa & Shear modulus in 1-2 plane. \\
\hline$\rho_{\text {comp }}$ & $=1600$ & $\mathrm{Kg} / \mathrm{m}^{3}$ & Material density. \\
\hline$v_{12}$ & $=0.275$ & & Poisson's ratio \\
\hline$v_{21}$ & 0.466 & & Poisson's ratio \\
\hline
\end{tabular}

$$
\begin{array}{llll}
\mathrm{L}_{\text {piezo }} & =0.1524 & \text { meter } & \text { Piezoelectric layer length. } \\
\mathrm{C} & =0.001778 & \text { meter } & \text { Piezoelectric layer thickness. }
\end{array}
$$

\begin{tabular}{|c|c|c|c|}
\hline $\mathrm{E}$ & $=82.047$ & $\mathrm{GPa}$ & Modulus of elasticity \\
\hline G & $=31.026$ & $\mathrm{GPa}$ & Shear modulus \\
\hline $\begin{array}{l}\rho_{\text {piezo }} \\
d_{31}\end{array}$ & $\begin{array}{l}=7500 \\
=-1.219 \times 10-10\end{array}$ & $\begin{array}{l}\mathrm{Kg} / \mathrm{m}^{3} \\
\mathrm{~m} / \mathrm{V}\end{array}$ & Piezoelectric material density. \\
\hline $\begin{array}{l}\mathrm{u}_{31} \\
\varepsilon_{33}^{s_{3}}\end{array}$ & $=1.475 \times 10-5$ & $\mathrm{~F} / \mathrm{m}$ & \\
\hline & $=0.046$ & $\mathrm{C} / \mathrm{m}^{2}$ & Electric permittivity constant. \\
\hline
\end{tabular}

Composite beam properties:

Piezoelectric properties: 
Table (1): Tip displacement of smart beam subjected to $12.4 \mathrm{kV}$.

\begin{tabular}{|c|c|c|c|}
\hline $\begin{array}{c}\text { Normalized tip } \\
\text { displacement }\end{array}$ & Saravanos [28] & Robbins [27] & Present Model \\
\hline w/a $\left(10^{-4}\right)$ & 1.9388 & 2.0393 & 1.9237 \\
\hline
\end{tabular}

The obtained normalized results are compared with reference $[27,28]$ and verification is done with a difference of $5.66 \%$ from Robbins et al. [27] results with model based on higher order theory, and difference of $0.77 \%$ from the results obtained by Saravanos et al. model [28] using the layer wise method.

\section{Example (2)}

In this example the number of elements used in the finite element problem is chosen to be thirty elements and the number of piezoelectric patches mounted on the upper surface of the [0/90] composite beam is three patches. The patches are fixed at elements numbers $(10,15$, and 20). The effect of PZT voltage variations with tip displacement and twist angles are obtained

The materials and geometric properties of the smart composite beam are given by:

Graphite/epoxy composite beam:

\begin{tabular}{|c|c|c|c|}
\hline $\mathrm{E}_{1}$ & $=144.8 \times 109$ & $\left(\mathrm{~N} / \mathrm{m}^{2}\right)$ & Modulus of elasticity in longitudinal direction \\
\hline $\mathrm{E}_{2}$ & $=9.65 \times 109$ & $\left(\mathrm{~N} / \mathrm{m}^{2}\right)$ & Modulus of elasticity in transverse direction. \\
\hline $\mathrm{G}_{12}$ & $=4.14 \times 109$ & $\left(\mathrm{~N} / \mathrm{m}^{2}\right)$ & Shear modulus. \\
\hline$v_{12}$ & $=0.3$ & & Poisson's ratio \\
\hline$\rho_{\text {comp }}$ & $=2800$ & $\left(\mathrm{~kg} / \mathrm{m}^{3}\right)$ & Material density. \\
\hline $\mathrm{L}$ & $=0.1524$ & (meter) & Beam length. \\
\hline a & $=0.01524$ & (meter) & Beam thickness. \\
\hline & 0.0254 & (meter) & Beam width. \\
\hline
\end{tabular}

A (G-1195) piezo-ceramic patches are used with inclination angle $(\beta)=45^{\circ}$ or $-45^{\circ}$ with the beam axis. The material properties are given in Example (1) with the following geometric properties:

Piezoelectric patch dimensions:

$\begin{array}{llll}\mathrm{L}_{\text {piezo }}=0.0254 & (\text { meter }) & \text { Piezoelectric patch length. } \\ \mathrm{C} & =0.000191 & (\text { meter }) & \text { Piezoelectric patch thickness. } \\ \mathrm{B}_{\text {piezo }}=0.00635 & \text { (meter) } & \text { Piezoelectric patch width. }\end{array}$

Table 2 shows the effect of increasing the voltage on inclined piezoelectric patches mounted on beam with zero mechanical loads. It also shows that as the applied voltage increases the static bending displacement as will as the twisting angle increases. As demonstrated on Figure 6 the twisting angle and transverse tip deflection change linearly with the voltage increase. 
Table 2: Effect of the voltage on the deformation of [0/90] composite beam with inclined piezoelectric patches.

\begin{tabular}{|c|c|c|c|c|c|c|}
\hline \multirow{2}{*}{$\begin{array}{c}\text { PZT } \\
\text { voltage } \\
\text { (Volt) }\end{array}$} & $\begin{array}{c}\text { Piezo } \\
\text { setting } \\
\text { angle } \\
\text { (degree) }\end{array}$ & $\begin{array}{c}\mathbf{P}(\mathbf{x}) \\
\mathbf{( N )}\end{array}$ & $\mathbf{S} \mathbf{N} / \mathbf{m})$ & $\begin{array}{c}\mathbf{T}(\mathbf{x}) \\
\mathbf{N} \cdot \mathbf{m} / \mathbf{m}\end{array}$ & $\begin{array}{c}\text { Tip } \\
\text { deflection } \\
\mathbf{1 0 ^ { - 5 }} \mathbf{( m )}\end{array}$ & $\begin{array}{c}\text { Tip twist } \\
\text { angle (rad) }\end{array}$ \\
\hline 0 & -45 & 0 & 0 & 0 & 0 & 0 \\
\hline 120 & -45 & 0 & 0 & 0 & 1.57 & 0.005530 \\
\hline 150 & -45 & 0 & 0 & 0 & 1.96 & 0.006913 \\
\hline 180 & -45 & 0 & 0 & 0 & 2.35 & 0.008295 \\
\hline 200 & -45 & 0 & 0 & 0 & 2.61 & 0.009217 \\
\hline 250 & -45 & 0 & 0 & 0 & 3.26 & 0.01152 \\
\hline 280 & -45 & 0 & 0 & 0 & 3.65 & 0.01290 \\
\hline 300 & -45 & 0 & 0 & 0 & 3.91 & 0.01382 \\
\hline 400 & -45 & 0 & 0 & 0 & 5.22 & 0.01843 \\
\hline 500 & -45 & 0 & 0 & 0 & 6.52 & 0.02304 \\
\hline 1000 & -45 & 0 & 0 & 0 & 13.04 & 0.04605 \\
\hline 2000 & -45 & 0 & 0 & 0 & 26.08 & 0.09203 \\
\hline 10000 & -45 & 0 & 0 & 0 & 130.5 & 0.45671 \\
\hline 12500 & -45 & 0 & 0 & 0 & 163.2 & 0.56943 \\
\hline
\end{tabular}

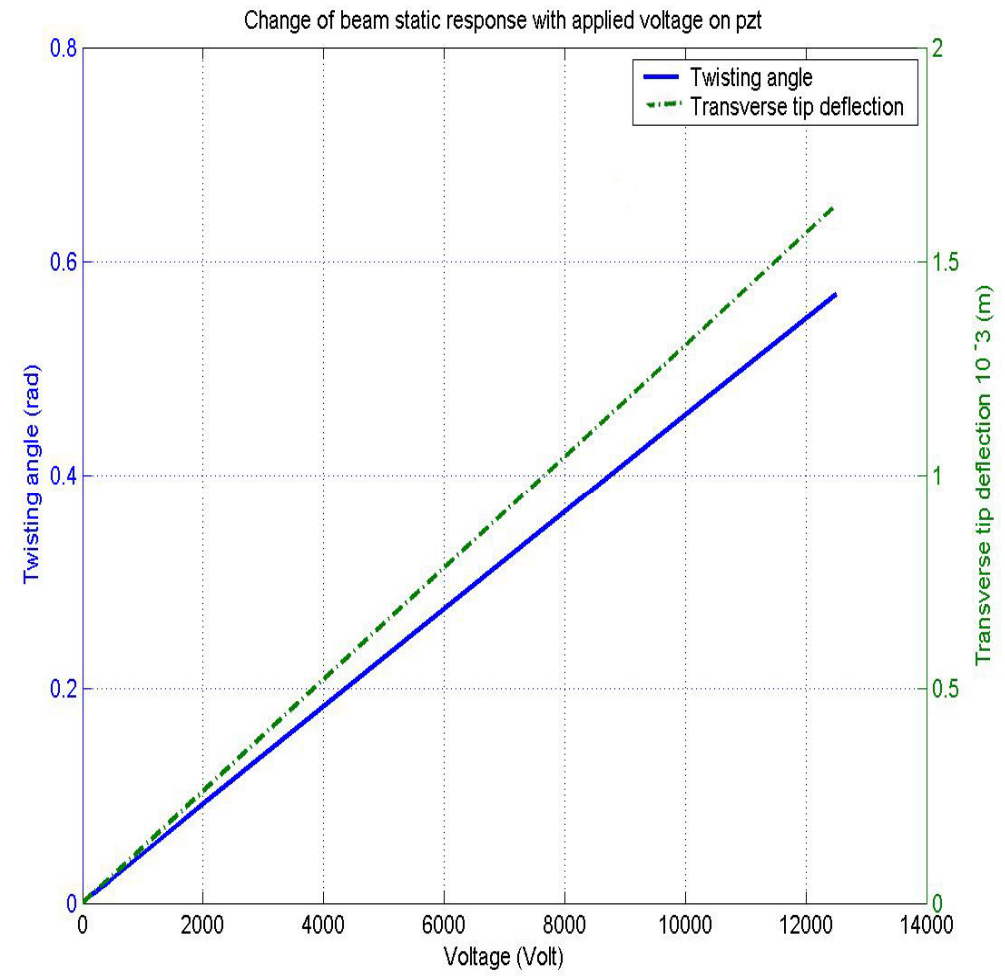

Figure 6: Beam response with the applied voltage on the inclined piezoelectric patches. 


\section{Example (3)}

In Table 3 we studied the effect of the applied voltages in addition to mechanical loads on a composite beam with fiber orientation angles [0/90] with inclined piezoelectric patch fixed at nodes $(10,15$, and 20$)$, by selecting a constant applied mechanical loads on the beam and variable voltage on the inclined piezoelectric patches. It is shown that as the voltage increases in a direction opposite to the direction of the applied transverse load and opposite to the polarization direction the tip deflection and twisting angle decrease.

Table 3: Deformation reduction for [0/90] composite beam with inclined piezoelectric material.

\begin{tabular}{|c|c|c|c|c|c|c|c|}
\hline \multirow{2}{*}{$\begin{array}{c}\text { PZT } \\
\text { voltage } \\
\text { (Volt) }\end{array}$} & \multirow{2}{*}{$\begin{array}{c}\text { Piezo } \\
\text { setting } \\
\text { angle } \\
(\stackrel{0}{ })\end{array}$} & \multicolumn{3}{|c|}{ Mechanical load } & \multirow{2}{*}{$\begin{array}{c}\text { Tip } \\
\text { deflection } \\
10-5(\mathrm{~m})\end{array}$} & \multirow{2}{*}{$\begin{array}{l}\text { Tip twist } \\
\text { angle } \\
\text { (rad.) }\end{array}$} & \multirow{2}{*}{$\begin{array}{l}\text { Percentage of } \\
\text { tip } \\
\text { displacement } \\
\text { reduction (\%) }\end{array}$} \\
\hline & & $\begin{array}{l}P(x) \\
(N)\end{array}$ & $\begin{array}{l}\Omega(x) \\
N / m\end{array}$ & $\begin{array}{c}T(x) \\
\text { N.m/ } \\
\text { m }\end{array}$ & & & \\
\hline \multicolumn{8}{|c|}{3 piezoelectric patches at nodes $(10,15$, and 20$)$ : } \\
\hline 0 & 0 & 2 & 2 & 2 & 9.112 & 0.136015 & ** \\
\hline 200 & 45 & 2 & 2 & 2 & 6.532 & 0.127258 & $6.44 \%$ \\
\hline 500 & 45 & 2 & 2 & 2 & 2.660 & 0.114115 & $16.10 \%$ \\
\hline 550 & 45 & 2 & 2 & 2 & 2.015 & 0.111924 & $17.71 \%$ \\
\hline 560 & 45 & 2 & 2 & 2 & 1.886 & 0.111486 & $18.03 \%$ \\
\hline 570 & 45 & 2 & 2 & 2 & 1.757 & 0.111047 & $18.35 \%$ \\
\hline 580 & 45 & 2 & 2 & 2 & 1.63 & 0.110609 & $18.68 \%$ \\
\hline 630 & 45 & 2 & 2 & 2 & 0.983 & 0.108417 & $20.29 \%$ \\
\hline
\end{tabular}

** Deflection with no voltage

The results shown in Table 3, are plotted in Figure 7 for both tip deflection and twisting angle.

\section{Example (4)}

The effect of thickness of the piezoelectric layer has been studied for the composite beam with configuration [0/90] with inclined piezoelectric patch. The following results were recorded in Table 4. With three piezoelectric patches placed at nodes number $(10,15$, and 20$)$ and zero mechanical loads. 


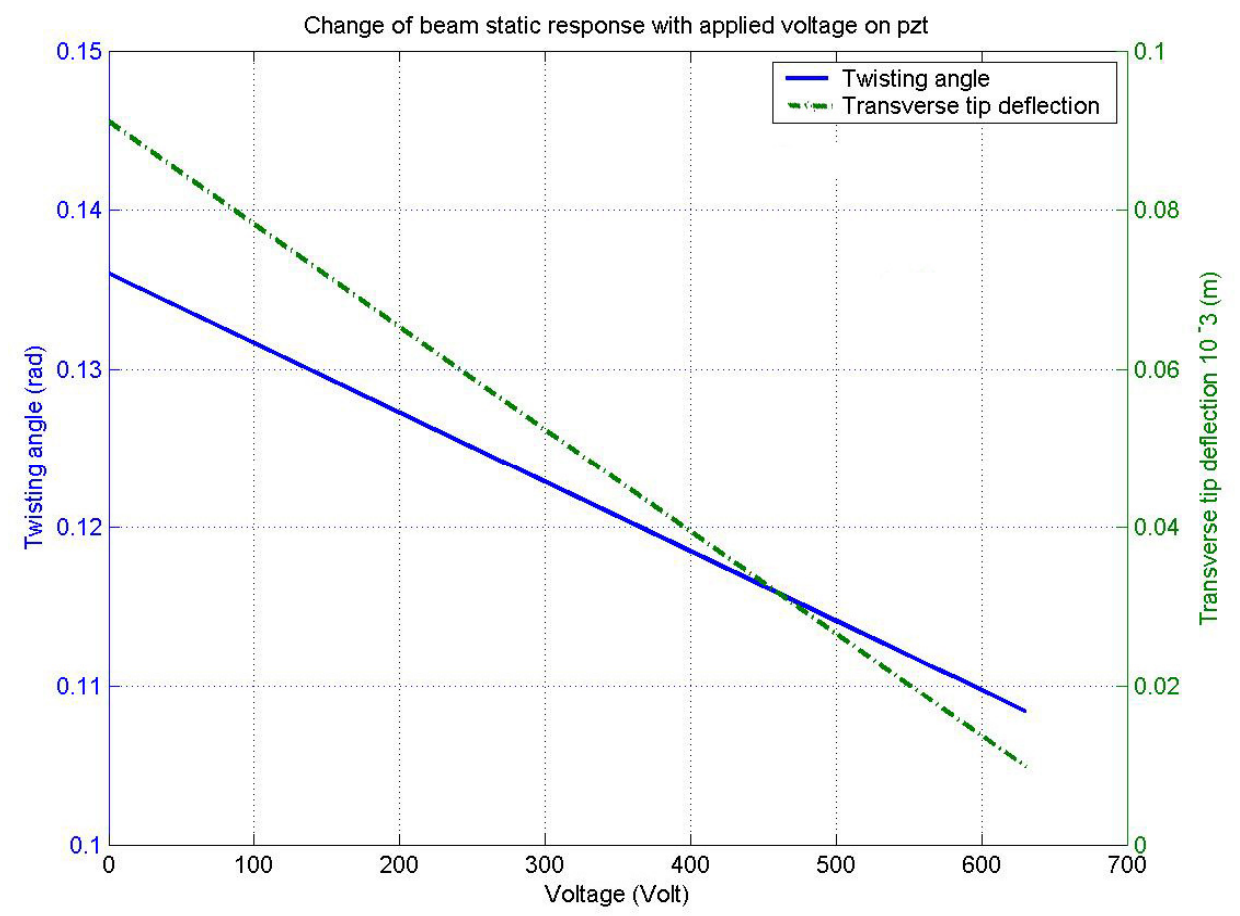

Figure 7: Deformation of beam when applying voltage on the three piezoelectric patches.

Table 4: Effect of piezoelectric patches thickness on the tip deflection and twist angle.

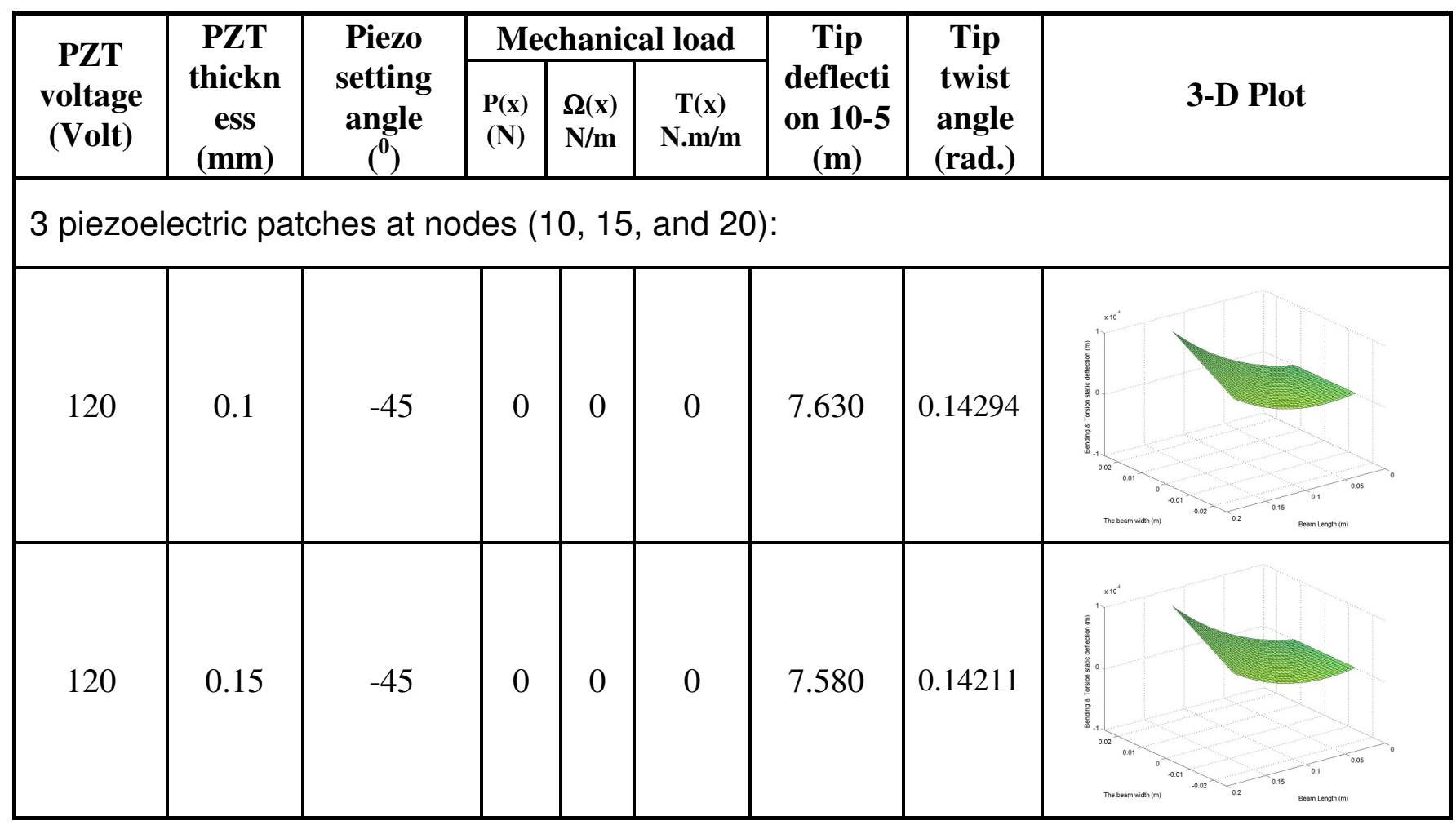


Table 4: Effect of piezoelectric patches thickness on the tip deflection and twist angle (Continued).

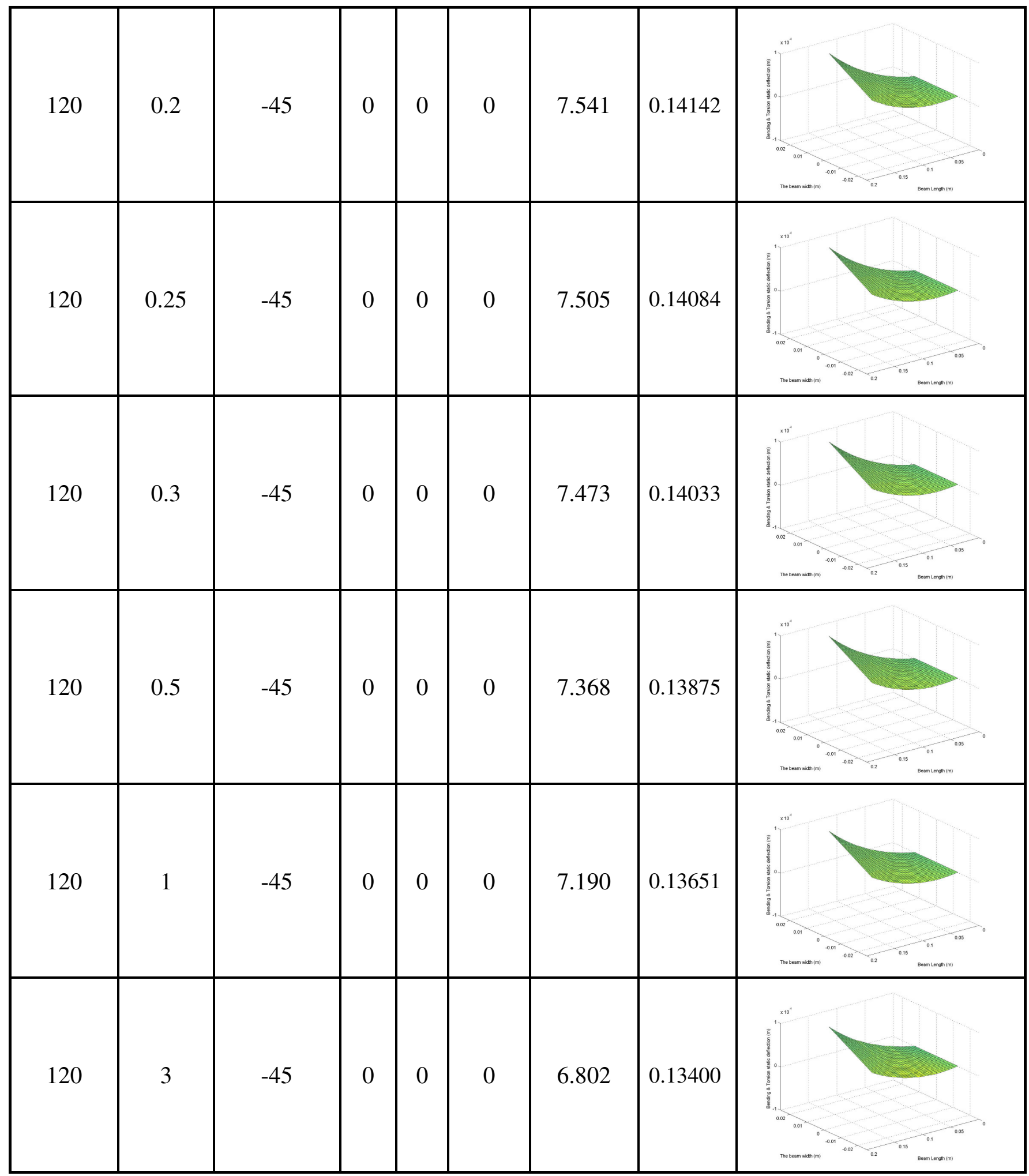

It is shown in Table (4) that when the piezoelectric material thickness increases from 0 to $1 \mathrm{~mm}$ both the twisting angle and the transverse tip deflection decreases nonlinearly, while decreasing linearly by increasing the PZT thickness from $1 \mathrm{~mm}$ to 
$3 \mathrm{~mm}$. The percentage reduction in tip displacement varies by about $6.29 \%$ when the thickness increases from 0 to $3 \mathrm{~mm}$. The percentage reduction of twist angle varies by about $8.1 \%$ for the same increase in PZT thickness.

Percentage reduction of twist angle $=\frac{0.143-0.134}{0.143} \times 100=6.29 \%$

Percentage reduction of tip displacement $=\frac{0.074-0.068}{0.074} \times 100=8.1 \%$

The obtained values are plotted in Figure (8).

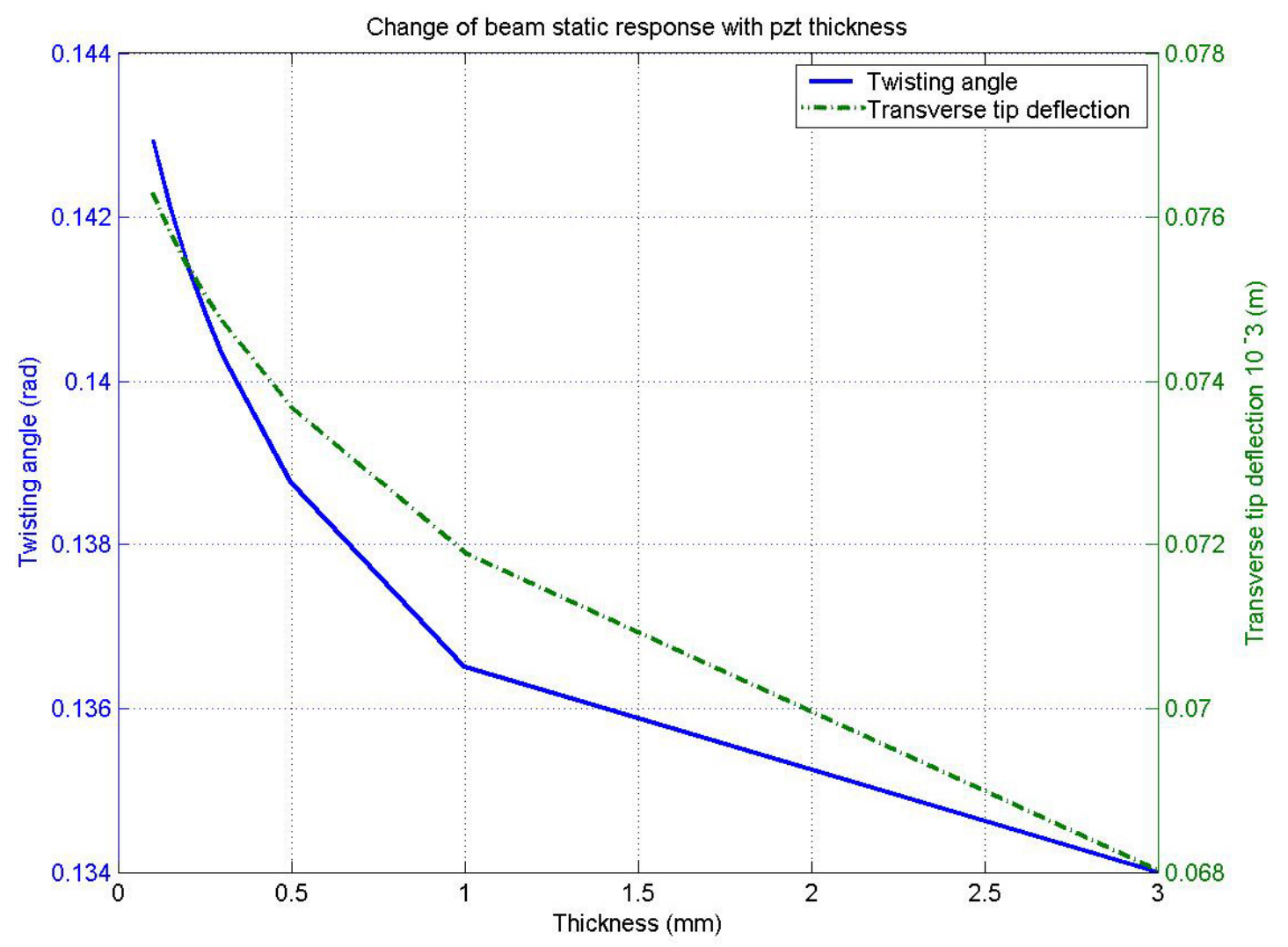

Figure 8: Effect of piezoelectric patch thickness on beam response.

The effect of fiber orientation angles of the beam material and the number of layers on the tip displacement and twist angle of beam are shown in Table 5 for different stacking sequences [0/90], [0/90/0], [0/90/0/90], [0/90/90/0], [0/45], [0/45/0/45], [0/45/45/0], and [45/-45/45/-45]. 
Table 5: Fiber orientation angles effect on the beam tip deflection and twist angle.

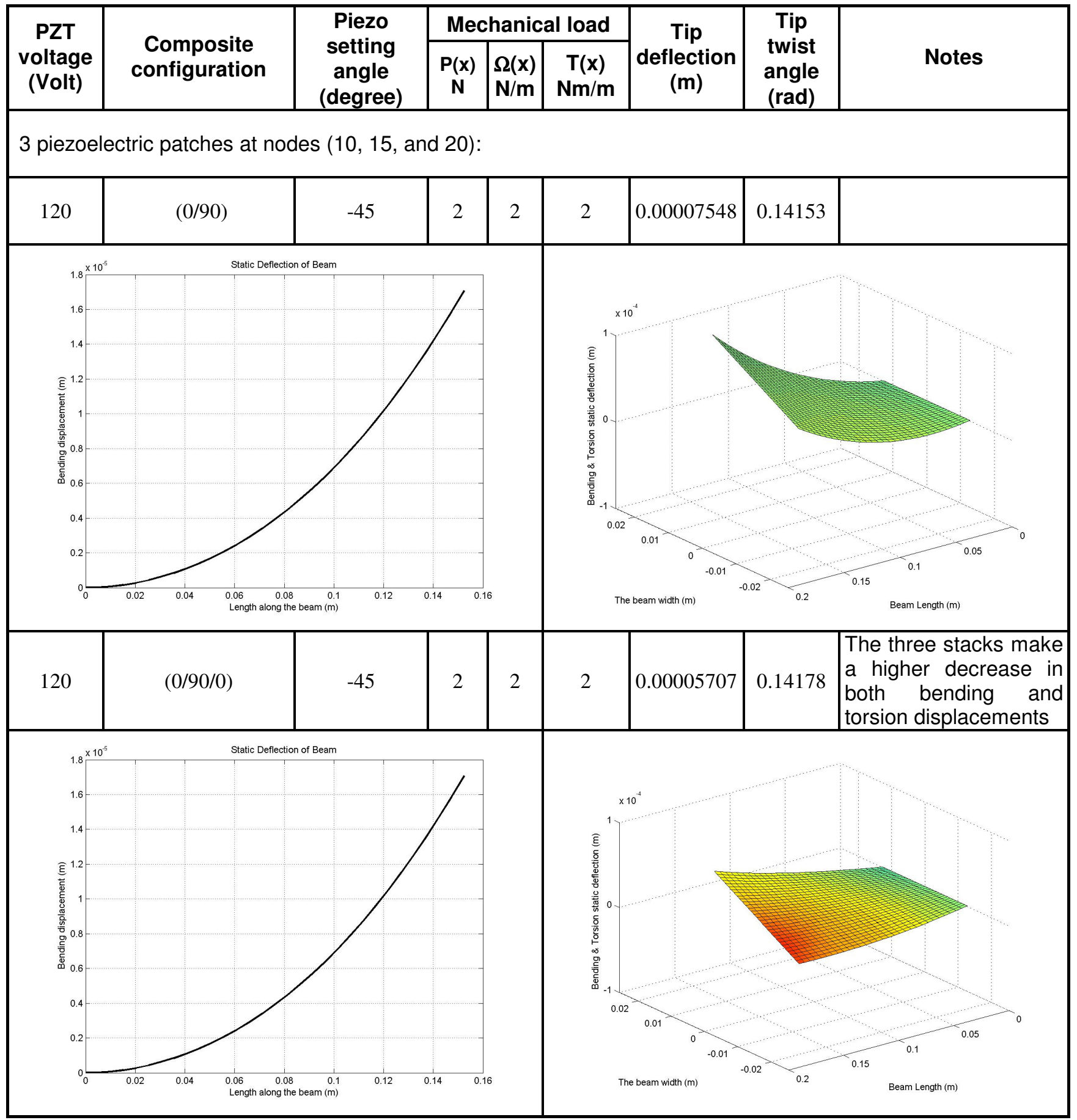


Table 5: Fiber orientation angles effect on the beam tip deflection and twist angle (Continued).

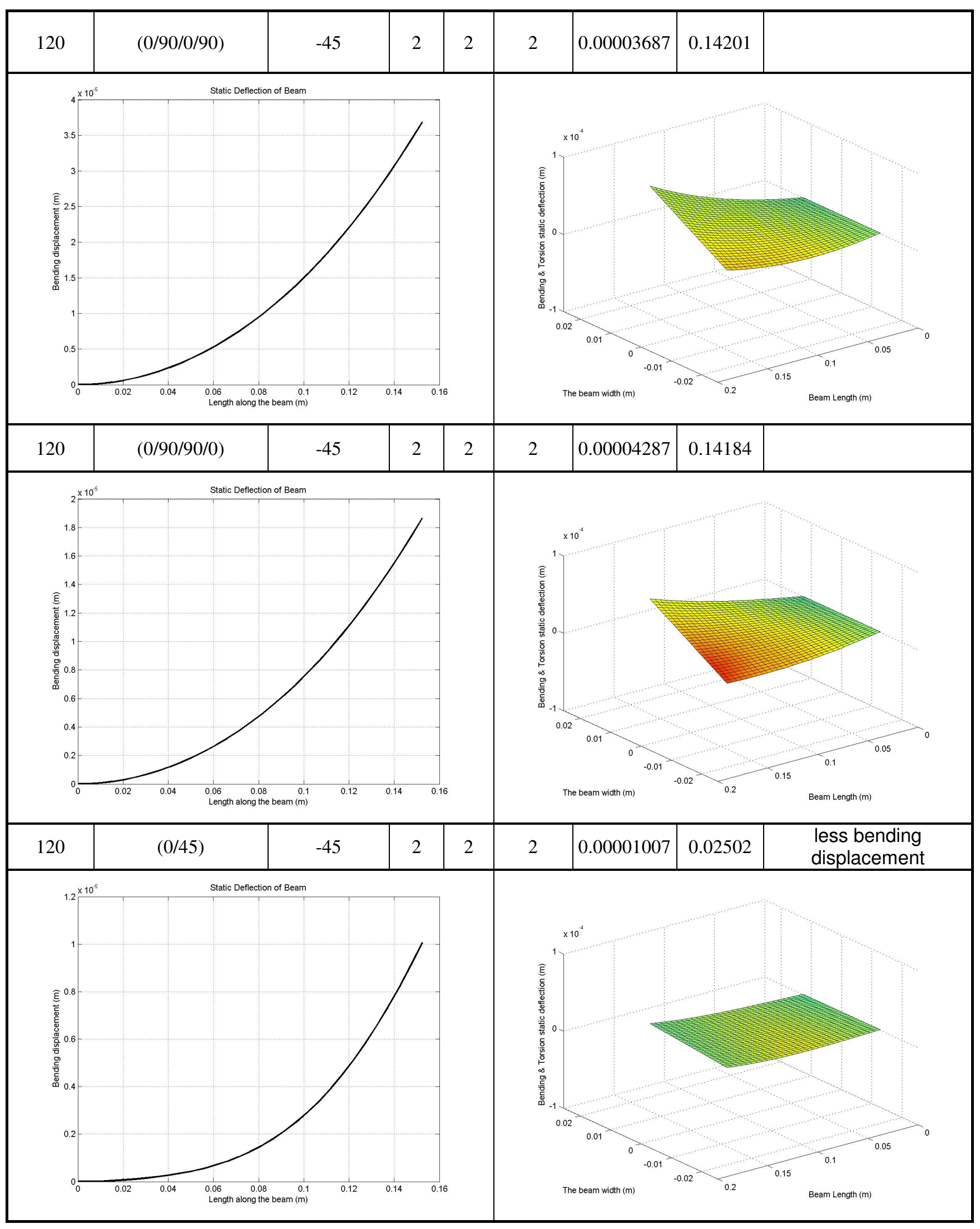


Table 5: Fiber orientation angles effect on the beam tip deflection and twist angle (Continued).

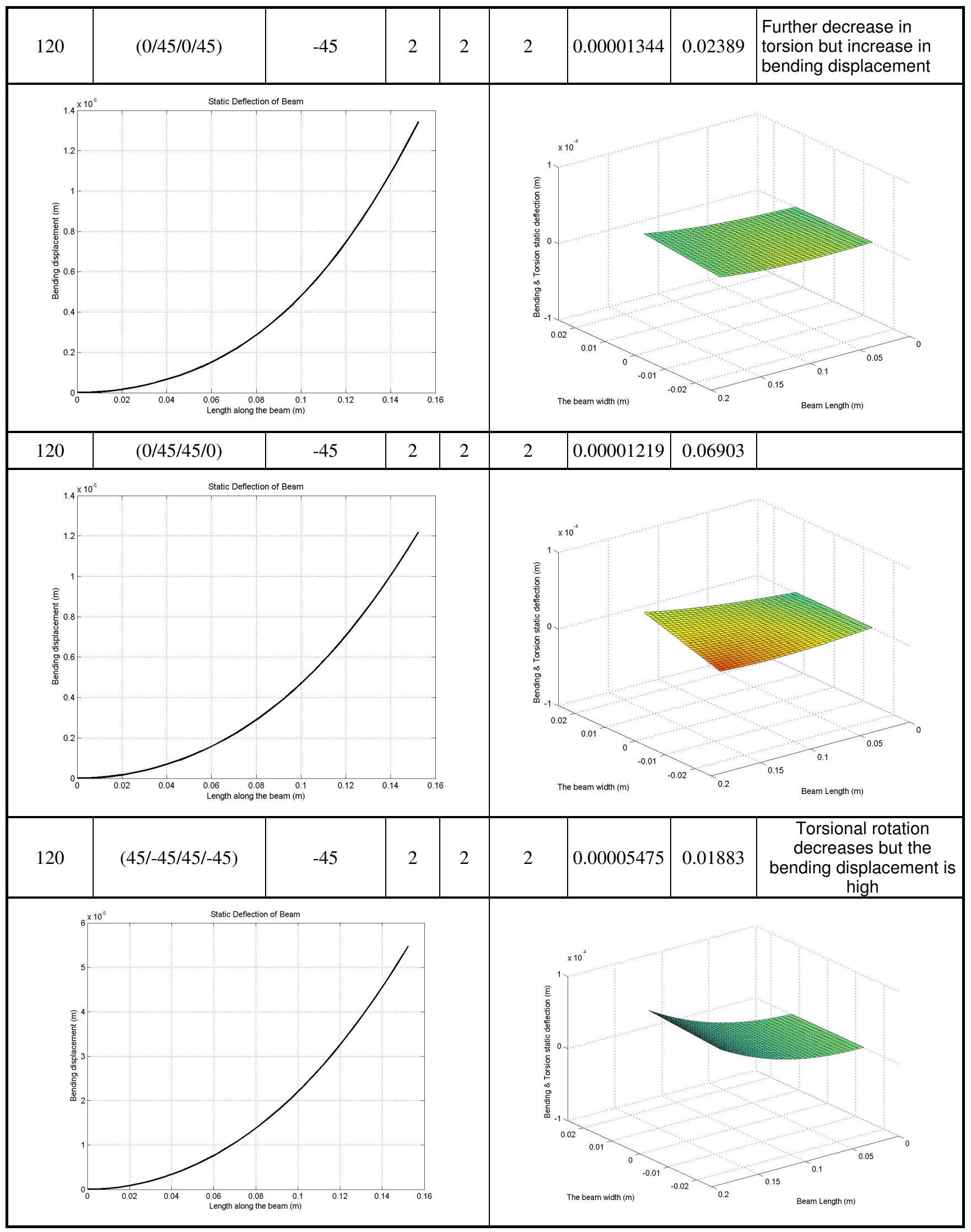


From Table 5, it is found that the three stacks with arrangement $(0 / 90 / 0)$ make a higher decrease in both bending and torsion displacements, less bending displacement obtained with laminate $(0 / 45)$, further decrease in torsion but an increase in bending displacement with laminate $(0 / 45 / 0 / 45)$. For the laminate with ($45 / 45 /-45 / 45)$ the torsional rotation decreases but the bending displacement is higher.

\section{CONCLUSIONS}

The following conclusions have been drawn:

1. The finite element model is obtained for orthotropic beam structure system with inclined piezoelectric actuators on the surface at an angle $\beta$ with the beam axis. The structure is subjected to axial, transverse, and torsion loads, in addition to the electrical load due to the piezoelectric patches. The developed code is verified by comparison to the published results for some special cases.

2. The maximum effective action of the piezoelectric patches in the torsion direction is obtained by an inclination angle equal to forty five degrees, increasing the number of patches, and/or increasing the applied voltage.

3. When piezoelectric patches thickness increases the response on twisting angle and transverse deflection decreases.

4. The [0/45] symmetric composite beams resist transverse deformation more than the twisting rotation while the asymmetric beams resist twisting rotation more than $(0 / 90)$ composite beams. The (0/90) asymmetric composite beams resist axial and transverse deflections more than the symmetric one.

5. The developed model can be used to investigate the control of static and dynamic response of compressor and turbine blades. The analytical results obtained can be verified more accurately by using experimental verification.

The axial and bending deformations of the beam can be controlled using piezoelectric patches aligned with the axis of the beam structure. On the other hand, the axial, bending and torsion deformations can be controlled by attaching the piezoelectric patches at an angle $\beta$ with the beam axis.

\section{REFERENCES}

[1] Sakawa Y. and Luo Z. H.; "Modeling and control of coupled bending and torsional vibrations of flexible beams"; IEEE Trans. Automatic Control 34, pp. 970-7, 1989.

[2] Banks H. T. and Smith C. A.; "Modeling of coupled bending and torsion in elastic structures"; ASME J. Vibr. Control Mech. Sys. 61, pp. 11-20, 1993. 
[3] Banerjee J. R. and Williams F. W.; "Coupled bending-torsional dynamic stiffness matrix of an axially loaded Timoshenko beam element"; Int. J. Solid Struct. 31 pp. 749-62, 1994.

[4] Suresh J. K., Venkatesan C. and Ramamurti V., 'Structural Dynamic analysis of composite beams', J. sound vibr, 143, pp. 503-19, 1990.

[5] Boresi A. P., Schmidt R. J. and Sidebottom O. M.; "Advanced Mechanics of Materials"; New York; Wiley pp 242-9, 1978.

[6] Sankar B. V.; "A beam theory for laminated composite and application to torsion problems"; ASME J. Appl. Mech. 60 pp. 246-9, 1993.

[7] A.Farid, M. Adnan Elshafei, 'Finite element analysis of compressor blade under extension bending and torsion loads', Part I: Isotropic Materials, asat.12,MTC, Egypt, 29-31 May 2007.

[8] A.Farid, M. Adnan Elshafei, and S. KOUSA, 'Finite element analysis of compressor blade under extension bending and torsion loads', Part II: Anisotropic Materials, AMME.13,MTC, Egypt, 27-29 May 2008.

[9] Crawley, E. F., and De luis, J., "Use of Piezoelectric Actuators as Elements of Intelligent Structures," AIAA Journal, Vol. 25, No, 10, 1987, pp. 1373-1385.

[10] Bailey, T., and Hubbard, J. E., Jr., "Distributed Piezoelectric polymer active Vibration Control of a Cantilever Beam", Journal of Guidance, control and dynamics, Vol. 8, No. 5, pp 605-611, 1985

[11] Peter C. Chen and Inderjit Chopra, 'Induced strain actuation of composite beams and rotor blades with embedded Piezoceramic elements', Smart Mater. Struct. , Vol. 5, pp. 35-48, 1996.

[12] Sunar M. and Rao S. S.,'Recent advances in sensing and control of flexible structures via piezoelectric materials technology', ASME Appl. Mech. Rev. 52, pp. 1-16, 1999.

[13] Benjeddou A., 'Advances in piezoelectric finite element modeling of adoptive structural elements: a survey', Comput. Struct., 76, pp. 347-63, 2002.

[14] Henno, Allik .and Huges, T. J.R., "Finite Element Method for Piezoelectric Vibration", Int. J. for Numerical Methods in Engineering, Vol. 2, pp. 151-157 (1970).

[15] Tzou, H. S., and Fu, H. Q., "A Study of Segmentation of Distributed Piezoelectric Sensors and Actuations, Part I: Theoretical Analysis" Journal of Sound and Vibration, Vol. 172, No. 2, pp. 247-259, 1994.

[16] K. Chandrashekhara and K. M. Bangera, "Free Vibration of Composite Beams using a Refined Shear Flexible Beam Element", Computer and Structures, Vol. 43, No. 4, 1992, p.p. 719-727.

[17] I.M. Bendary, M.A. Elshafei and A.M. Riad, " Finite Element Model of Smart Beams with Distributed Piezoelectric Actuators ", J. of Intelligent Material Systems and Structures, Vol. 21, 2010, pp. 747-758.

[18] Christopher park \& Inderjit chopra,1994,"Modeling piezoceramic actuation of beam in torsion", AIAA/ASME Adaptive structures forum, AIAA-94-1781-cp, pp438-450

[19] Park C., Walz C., \& Chopra I., 1993, "Bending and torsion models of beams with induced strain actuators", SPIE conf. Albuquerque, NM.

[20] Takawa T., Fu kuda T.\& Takada T, 1997."Flexural-Torsion coupling vibration control of fiber composite cantilevered beam by using piezoceramic actuators", Smart Mat. Struct., 6, pp447-484. 
[21] P.C. Chen \& In. Chopra, 1996, "Induced strain actuation of composite beams and rotor blades with embedded piezoelectric elements", smart mater. Struct. S,U.K., pp35-48

[22] A. M. Farid and M. Adnan Elshafei, 'Modeling and analysis of piezoelectric actuation of smart compressor blade in torsion', Advanced materials for application in acoustics and vibration, BUE Conf., Cairo-Egypt, 4-6 January, 2009.

[23] Whitney J. M, "Analysis of anisotropic laminated plates subjected to torsional loading", Composites Eng, 3, 567-582, 1993.

[24] J. F. Nye, "Physical Properties of Crystals", Oxford Univ. Press. Inc. Printed in the USA, 1985, pp.110-115.

[25] Tiersten, H.F.1969, Linear piezoelectric plate vibration, plenum, N.Y.

[26] C. Park and Inderjit Chopra, 'Modeling Piezoceramic actuation of beams in torsion', 35th struct., struc. Dynamics, mater.conf. \& adaptive struct. forum, pp. 438-450, 18-21 April 1994.

[27] D.H. Robbins and J.N. Reddy, "Analysis of Piezoelectrically Actuated Beams Using A Layer-Wise Displacement Theory", J. of Computers \& Structures, Vol. 41, No.2, 1991, pp. 265-279.

[28] D.A. Saravanos and P.R. Heyliger, "Coupled Layerwise Analysis of Composite Beams with Embedded Piezoelectric Sensors and Actuators", J. of Intelligent Material Systems and Structures, Vol. 6, 1995, pp. 350-363.

[29] Clinton Y K Chee, L. Tong and P.S. Grant, "A mixed Model for Composite Beams with Piezoelectric Actuators And Sensors", Smart Materials and Structures, Vol. 8 (1999) 417-432.

[30] R.D. Cook, D.S. Malkus and M.E. Plesha, "Concept and Applications of Finite Element Analysis", 3rd Edition, John Wiley \& sons, NY, USA, 1974, p. 96 , 101

[31] J.N. Reddy, "Mechanics of Laminated Composite Plates and Shells, Theory and Analysis", 2nd edition, CRC Press, USA, 2004, p102.

\section{APPENDIX A}

The reduced stiffness components $Q_{i j}$ are related to the engineering constants as follows [31]:

$$
\begin{array}{ll}
Q_{11}^{k}=\frac{E_{1}^{k}}{1-v_{12}^{k} v_{21}^{k}} & Q_{12}^{k}=\frac{v_{12}^{k} E_{2}^{k}}{1-v_{12}^{k} v_{21}^{k}} \quad Q_{22}^{k}=\frac{E_{2}^{k}}{1-v_{12}^{k} v_{21}^{k}} \\
Q_{44}^{k}=G_{23} & Q_{55}^{k}=G_{13}^{k} \quad Q_{66}^{k}=G_{12}^{k}
\end{array}
$$

where; $E_{i}$ is the modules in $x_{i}$ direction, $G_{i j}(i \neq j)$ are the shear modules in the $x_{i}-x_{j}$ plane, and $v_{i j}$ are the associated Poisson's ratios.

The transformed reduced stiffness coefficients $\bar{Q}_{i j}$ are represented by: 


$$
\begin{aligned}
& \overline{\mathrm{Q}}_{11}=Q_{11} \cos ^{4} \theta+2\left(\mathrm{Q}_{12}+2 Q_{44}\right) \cos ^{2} \theta \sin ^{2} \theta+Q_{22} \sin ^{4} \theta \\
& \overline{\mathrm{Q}}_{12}=\left(Q_{11}+Q_{22}-4 Q_{44}\right) \cos ^{2} \theta \sin ^{2} \theta+Q_{12}\left(\cos ^{4} \theta+\sin ^{4} \theta\right) \\
& \overline{\mathrm{Q}}_{14}=\left(Q_{11}-2 Q_{44}-Q_{12}\right) \cos ^{3} \theta \sin \theta+\left(Q_{12}-Q_{22}+2 Q_{44}\right) \cos \theta \sin ^{3} \theta \\
& \overline{\mathrm{Q}}_{22}=Q_{11} \sin ^{4} \theta+2\left(Q_{12}+2 Q_{44}\right) \cos ^{2} \theta \sin ^{2} \theta+Q_{22} \cos ^{4} \theta \\
& \overline{\mathrm{Q}}_{24}=\left(Q_{11}-2 Q_{44}-Q_{12}\right) \cos \theta \sin ^{3} \theta+\left(Q_{12}-Q_{22}+2 Q_{44}\right) \cos ^{3} \theta \sin \theta \\
& \overline{\mathrm{Q}}_{44}=\left(Q_{11}+Q_{22}-2 Q_{44}\right) \cos ^{2} \theta \sin ^{2} \theta+Q_{44}\left(\cos ^{4}+\sin ^{4} \theta\right) \\
& \overline{\mathrm{Q}}_{55}=Q_{55} \cos ^{2} \theta+Q_{66} \sin ^{2} \theta \\
& \overline{\mathrm{Q}}_{56}=\left(Q_{55}-Q_{66}\right) \cos \theta \sin \theta \\
& \overline{\mathrm{Q}}_{66}=Q_{55} \sin ^{2} \theta+Q_{66} \cos ^{2} \theta
\end{aligned}
$$

